\title{
The Psychology of Terrorism : Understanding and Implication for Policies
}

\author{
Dr. Bhargavi Chatterjea Bhattacharyya \\ Consultant Psychiatrist
}

Compared with general public, terrorists do not exhibit unusually high rates of clinical psychopathology, irrationality, or personality disorders. The backgrounds of the terrorists are very diverse and there is no one set profile. In fact, barring lone wolf terrorism, there does not seem to be much link with personality or psychopathology.

When we analyze the behavior of others, we tend to attribute it to personal disposition instead of situational factors. This is the Fundamental Attribution Error (Lee Ross). The importance of situational factors has been demonstrated by Milgram's experiment and Stanford Prison experiment. The Staircase to Terrorism illustrates how persons are radicalized and their mindsets shift over a period of time as they move from one floor of the staircase to another.

Everybody starts on the ground floor. Their basic goals are like our goals, e.g. improvement in education, job opportunities etc. Some of these people who are dissatisfied, move to the First Floor. Here, some individuals feel their paths are blocked . They feel very frustrated and move on to the Second Floor.

In the Second Floor, we see displacement of aggression. Individuals blame 'others' for their frustration. And, some of the individuals now move up to the Third Floor. There is a shift of morality that endorses terrorism. But, attitudes do not always lead to action. There is further radicalization as one moves up to the Fourth Floor. Now, the main psychological process is categorical thinking. The "us versus them" thinking. "We are right, they are wrong" thinking. And this allows the other group to be labeled as sinful, and exterminating them is morally justified.
The Fifth or final floor is when inhibitory mechanisms are sidestepped. Variation of Milgram's experiments show people were reluctant to shock their victims when the victim was present in the room, or delivering the shock involved touching the victim. Participants of the experiment delivered lethal levels of sham electric shock when the victim was separated by a screen. These demonstrate that there are in-built psychological mechanisms that inhibit killing other human beings. Side stepping these inhibitory mechanism culminate in the ultimate act of terrorism. Traditionally, looking at psychological profile of terrorists and focusing on individualistic research had not been fruitful. Moghaddam has proposed that there are two types of behavior: a first that is causally determined and a second that is normatively regulated. Population norms, desire to conform to the society with whom they identify are powerful predictors of behavior.

In the transformation of an individual on the ground floor of the staircase to the radicalized terrorist, the central theme is threatened collective identity. When people feel that their identity is being directly threatened that acts as an important motivation for action. Many traditional and fundamentalist individuals feel threatened by globalization and the liberalization of gender roles.

Studies suggest that large-scale military responses to terrorism tend to be ineffective or temporarily to increase terrorist activity. Researchers have found that military responses to international terrorism can unwittingly reinforce terrorists' views of their enemies as aggressive, make it easier for them to recruit new members, and strengthen alliances among terrorist organizations. 
At one point of time, terrorism was synonymous with Al Qaeda. And despite the fact that 70 percent of Al Qaeda's core leadership has been caught or killed, terrorism is still an important issue today. Other groups like Islamic State have come to the fore.

Most government policies are directed towards people at the Fifth floor of the staircase. This results in people from lower floors coming up and replacing individuals on the Fifth floor. This short term focus should shift to more comprehensive long term focus. Policies must be revised to address foundational problems at the bottom of the staircase and to encourage the development of contextualized democracies.

\section{REFERENCES}

1. The Staircase to Terrorism A Psychological Exploration : Fathali M. Moghaddam

2. How social science can reduce terrorism. Chronicle of Higher Education, pp. B9-B10. Plous, S., \& Zimbardo, P. G. 